\title{
Effects of choline on the phenotype of the cultured bovine preimplantation embryo
}

\author{
E. Estrada-Cortés, ${ }^{1,2}$ ๑) V. M. Negrón-Peréz, ${ }^{3} \odot$ P. Tríbulo, ${ }^{4,5,6}$ M. G. Zenobi, ${ }^{4}$ C. R. Staples, ${ }^{1}$ () \\ and P. J. Hansen ${ }^{1 *}$ (1) \\ ${ }^{1}$ Department of Animal Sciences, D.H. Barron Reproductive and Perinatal Biology Research Program, and Genetics Institute, \\ University of Florida, Gainesville 32611-0910 \\ ${ }^{2}$ Campo Experimental Centro Altos de Jalisco, Instituto Nacional de Investigaciones Forestales, Agrícolas y Pecuarias, Tepatitlán de Morelos, \\ Jalisco, México 47600 \\ ${ }^{3}$ Department of Animal Sciences, University of Puerto Rico-Mayagüez, Mayagüez, Puerto Rico 00681 \\ ${ }^{4}$ Instituto de Reproducción Animal Córdoba, and Consejo Nacional de Investigaciones Cientificas y Tecnicas, Córdoba, Argentina X5145 \\ ${ }^{5}$ Facultad de Ciencias Agropecuarias, Universidad Nacional de Cordoba, Córdoba, Argentina X5000 \\ ${ }^{6}$ Consejo Nacional de Investigaciones Cientificas y Tecnicas (CONICET), Córdoba, Argentina, X5000
}

\section{ABSTRACT}

Choline is a precursor of acetylcholine, phosphatidylcholine, and the methyl-donor betaine. Reports indicate that supplementation with rumen-protected choline improves postpartum reproductive function of dairy cows. The objective was to determine whether addition of choline to culture medium of in vitro-produced embryos alters the phenotype of the resultant blastocysts. Treatments were choline chloride $(\mathrm{ChCl} ; 0.004,1.3,1.8$, and $6.37 \mathrm{mM})$ and phosphatidylcholine $(1.3 \mathrm{mM})$. Treatment with $0.004 \mathrm{mM} \mathrm{ChCl}$ improved development to the blastocyst stage, increased blastocyst cell number, and increased the percentage of blastocysts that were hatching or hatched. Development was not affected by higher concentrations of $\mathrm{ChCl}$ but was reduced by 1.3 $\mathrm{m} M$ phosphatidylcholine. Treatment of embryos with $1.3 \mathrm{mM} \mathrm{ChCl}$ (but not other concentrations) increased expression in blastocysts of 11 of 165 genes examined (AMOT, NANOG, HDAC8, HNF4A, STAT1, MBNL3, SOX2, STAT3, KDM2B, SAV1, and GPAM) and decreased expression of one gene (ASS1). Treatment with $1.3 \mathrm{~m} M \mathrm{ChCl}$ decreased global DNA methylation at $\mathrm{d}$ 3.5 of development and increased DNA methylation at d 7.5 in blastocysts. Treatment with $1.8 \mathrm{mM} \mathrm{ChCl}$ also increased methylation in blastocysts. In conclusion, addition of choline to the culture medium alters the phenotype of preimplantation bovine embryos produced in vitro. Choline chloride can act in a concentrationdependent manner to alter development, expression of specific genes, and DNA methylation.

Key words: choline, embryo, blastocyst, gene expression, DNA methylation

Received March 26, 2020.

Accepted June 11, 2020.

*Corresponding author: pjhansen@ufl.edu

\section{INTRODUCTION}

About $50 \%$ of the embryonic loss in lactating dairy cows transpires during the first week after fertilization (Wiltbank et al., 2016). Essential biological events occurring in the embryo during this period include cell proliferation, epigenetic reprograming (Jiang et al., 2018), activation of the embryonic genome (Graf et al., 2014), and the first lineage differentiation events culminating in the bilaminar blastocyst (Pfeffer, 2018). Understanding the embryonic and maternal determinants of the embryo's capacity for successful development to the blastocyst stage could be vital for new strategies to improve fertility in dairy cows.

Nutritional status is one of the important maternal determinants of reproductive function of dairy cows (Butler, 2000; Roche et al., 2011; Rodney et al., 2018). Among the strategies to improve the likelihood of a successful pregnancy after insemination is the administration of specific nutrients that play important functions in cellular biology. For example, the intramuscular injection of vitamin $\mathrm{E}$ and selenium at d 30 postpartum reduced services per conception and interval from calving to conception (Aréchiga et al., 1998). Supplementation with rumen-protected methionine between 30 and $126 \mathrm{~d}$ in milk increased conceptus size (amniotic vesicle volume and embryo diameter) in multiparous cows and reduced pregnancy loss (Toledo et al., 2017). Similarly, supplementation with rumen-protected choline (RPC) during the transition period improved conception rate after AI (Scheer-Oelrichs, 2003; Ardalan et al., 2010; Zenobi et al., 2018a).

Nutrients such as methionine and choline are key methyl donors for DNA methylation (Glier et al., 2014). Methylation of DNA increases from the 6- to 8-cell stage of development to the blastocyst stage (Dobbs et al., 2013; Jiang et al., 2018). Addition of me- 
thionine to culture medium increased the percentage of bovine embryos becoming blastocysts in vitro (Bonilla et al., 2010) and feeding supplemental methionine to superovulated cows changed the transcriptomic profile of flushed blastocysts (Peñagaricano et al., 2013).

Other metabolites of choline could also conceivably affect embryonic development. For example, products of phosphatidylcholine metabolism can regulate transcription through binding to peroxisome proliferatoractivated receptor- $\alpha$ (Chakravarthy et al., 2009). Choline can be metabolized by cells in several ways including through acetylation to form the cell-signaling molecule acetylcholine, phosphorylation to initiate formation of the phospholipid phosphatidylcholine, and oxidation to generate the methyl donor betaine (Fisher et al., 2002). The preimplantation bovine embryo expresses transcripts for the enzymes that metabolize choline through these pathways (Ikeda et al., 2010; Jiang et al., 2014). In mice, addition of acetylcholine to culture medium rescues embryos that experience a block in development at the 2-cell stage (Cho et al., 2009). Knockout of the gene for choline kinase (the first enzyme in the pathway to synthesize phosphatidylcholine) causes embryo lethality between d 3.5 and 7.5 of development (Wu et al., 2008). Knockdown of the gene for betaine-homocysteine methyltransferase, which removes a methyl group from betaine, decreases the proportion of embryos developing to the blastocyst stage (Lee et al., 2012).

The purpose of the series of experiments described here was to use the in vitro-produced embryo as a model to explore whether positive effects of feeding RPC on fertility of postpartum dairy cows (Scheer-Oelrichs, 2003; Ardalan et al., 2010; Zenobi et al. 2018a) might reflect actions of choline to modify development of the preimplantation embryo. The hypothesis was that the addition of choline to culture medium would alter the phenotype of preimplantation embryos by improving embryo development and by altering gene expression and amount of DNA methylation.

\section{MATERIALS AND METHODS}

\section{Embryo Production}

Procedures for embryo production are described in detail elsewhere (Tríbulo et al., 2019b). Bovine ovaries from cattle of undetermined breeds were obtained from an abattoir. Cumulus-oocyte complexes (COC) were recovered by bisecting follicles of 3 to $8 \mathrm{~mm}$ diameter using a scalpel and by vigorously rinsing the ovaries in a bath of oocyte collection medium (MOFA Global, Verona, WI). Fluid containing $\mathrm{COC}$ was filtered in a $100-\mu \mathrm{m}$ cell strain and rinsed with $12 \mathrm{~mL}$ of warm oocyte collection medium and poured into a Petri dish. The COC were washed 3 times with oocyte collection medium in an X-plate and only those with at least 3 layers of compact cumulus cells and a homogeneous cytoplasm were included in experiments. The COC were matured in groups of 10 in $50-\mu \mathrm{L}$ microdrops containing a commercial oocyte maturation medium (IVF-Bioscience, Falmouth, Cornwall, UK). Maturation drops were covered with mineral oil (Sigma Aldrich, St Louis, MO) and incubated for 22 to $24 \mathrm{~h}$ at $38.5^{\circ} \mathrm{C}$ and $5 \%$ (vol/vol) $\mathrm{CO}_{2}$ in a humidified atmosphere.

Matured COC were washed 3 times in HEPESbuffered Tyrode's albumin-lactate-pyruvate (HEPESTALP). For fertilization, groups of up to 300 were placed in a plate containing $1,700 \mu \mathrm{L}$ of in vitro fertilization Tyrode's albumin-lactate-pyruvate (IVF-TALP). Conventional frozen semen from a pool of 3 sires of various breeds was thawed and purified by centrifugation at $1,000 \times g$ for $10 \mathrm{~min}$ at room temperature in PureSperm 40/80 gradient (Nidacon International AB, Mölndal, Sweden). A second centrifugation was performed at $5,000 \times g$ for 5 min in HEPES-TALP and the pellet of semen was diluted to $600 \mu \mathrm{L}$ of IVF-TALP, and after calculation of sperm number, the pellet was diluted again to have a concentration of $17 \times 10^{6}$. Insemination was performed by adding $120 \mu \mathrm{L}$ of sperm and $80 \mu \mathrm{L}$ of a solution containing $0.5 \mathrm{mM}$ penicillamine, $0.25 \mathrm{~m} M$ hypotaurine, and $25 \mu M$ epinephrine. The final sperm concentration in the plate was $1 \times 10^{6} /$ $\mathrm{mL}$.

Fertilization plates were incubated for 15 to $16 \mathrm{~h}$ at $38.5^{\circ} \mathrm{C}$ and $5 \%$ (vol/vol) $\mathrm{CO}_{2}$ in a humidified atmosphere. Cumulus cells were removed by vortexing putative zygotes for $5 \mathrm{~min}$ in a tube containing 1,000 U/ $\mathrm{mL}$ hyaluronidase and approximately $50 \mu \mathrm{L}$ of HEPESTALP. Presumptive zygotes (i.e., oocytes exposed to sperm) were washed 3 times in HEPES-TALP and then placed in groups of 25 to 30 in $50-\mu \mathrm{L}$ microdrops of culture medium covered with mineral oil. The culture medium was either BBH7 (Cooley Biotech, Gainesville, FL; Block et al., 2010) or synthetic oviduct fluid-bovine embryo 2 (SOF-BE2; Tríbulo et al., 2019b). Culture medium contained various treatments as described for each experiment. Microdrops were incubated at $38.5^{\circ} \mathrm{C}$ in a humidified atmosphere of $5 \% \mathrm{CO}_{2}$ ( $\mathrm{vol} / \mathrm{vol}$ ), $5 \%$ $\mathrm{O}_{2}$ ( $\left.\mathrm{vol} / \mathrm{vol}\right)$, and $90 \% \mathrm{~N}_{2}$ ( vol/vol). The percentage of presumptive zygotes that cleaved (any structure $\geq 2$ blastomeres) after insemination was evaluated at $\mathrm{d} 3$ after insemination and the percentage of presumptive zygotes and cleaved embryos that developed to the blastocyst stage was evaluated at d 7.5. In addition, blastocysts were classified as to whether or not they were either hatching or hatched from the zona pellucida. 


\section{Experimental Design and Treatments}

A total of 4 experiments was performed using embryos treated with vehicle or various concentrations $(0.004,1.3,1.8$, and $6.37 \mathrm{mM})$ of choline chloride (Sigma-Aldrich, St. Louis, MO) or phosphatidylcholine (Sigma-Aldrich). Phosphatidylcholine was derived from soybean. Fatty acid content was approximately 13\% C16:0 (palmitic), 4\% C18:0 (stearic), 10\% C18:1 (oleic), 64\% C18:2 (linoleic), and 6\% 18:3 (linolenic) with other fatty acids being minor components. The choline concentrations used in experiments were chosen based on values for plasma concentrations of free choline and choline metabolites (betaine, phosphocholine, glycerophosphocholine, lysophosphatidylcholine, phosphatidylcholine, and sphingomyelin) in lactating Holstein cows as described by Artegoitia et al. (2014). Concentrations were chosen based on the lowest amounts of choline in the blood early postpartum (7 DIM) and around the time when cows are typically first inseminated (70 DIM). The $0.004 \mathrm{~m} M$ value represents concentrations of choline chloride at 7 DIM, whereas concentrations of 1.30 and $6.37 \mathrm{mM}$ represent total choline (the sum of concentrations of choline and choline metabolites) in plasma at 7 DIM $(1.3 \mathrm{mM})$ and 70 DIM $(6.37 \mathrm{mM})$. The concentration of $1.8 \mathrm{~m} M$ represents the approximate total choline at 7 DIM for cows fed 60 $\mathrm{g} / \mathrm{d}$ of a RPC product, assuming that feeding caused an increase in total choline of $0.5 \mathrm{mM}$ (M. G. Zenobi and C. R. Staples, unpublished). Phosphatidylcholine was tested because it constitutes the main choline metabolite in plasma. The concentration tested $(1.3 \mathrm{mM})$ was based on total choline in plasma at 7 DIM. Concentration of phosphatidylcholine varies from $1 \mathrm{~m} M$ at $\mathrm{d} 7$ to $1.7 \mathrm{~m} M$ at 21 DIM.

Each experiment was conducted in several replicates in which $\sim 200$ to 300 putative zygotes (i.e., oocytes exposed to sperm during fertilization) were randomly assigned to treatment by being cultured in culture medium with one of several concentrations of choline chloride or phosphatidylcholine. All treatments were isotonic to each other by adding sodium chloride so that the final concentration of supplemental choline chloride and sodium chloride was the same for all treatments. Thus, the vehicle (i.e., $0 \mathrm{~m} M$ choline) contained an amount of additional sodium chloride equivalent to the highest concentration of choline chloride tested.

Experiment 1 ( $\mathrm{n}=5$ replicates) was performed to determine the effects of the addition of choline chloride to $\mathrm{BBH} 7$ culture medium on development to blastocyst stage and gene expression on the resultant blastocysts. Presumptive zygotes were treated with either $0(\mathrm{n}=$ 331), 1.3 (302), $1.8(\mathrm{n}=300)$, or $6.37(\mathrm{n}=329) \mathrm{m} M$ choline chloride from d 0 to 7.5 of development. Experi- ment $2(\mathrm{n}=7$ replicates) was performed to determine whether culture medium affects embryonic response to choline. Presumptive zygotes were assigned to 1 of 4 treatments in a $2 \times 2$ factorial arrangement. The main factors in this design included choline chloride at 0.0 $\mathrm{m} M(\mathrm{n}=679)$ or $1.3 \mathrm{~m} M(\mathrm{n}=689)$ and culture medium with BBH7 $(\mathrm{n}=687)$ or SOF-BE2 $(\mathrm{n}=681)$. An average of 342 putative zygotes was present per treatment combination. Endpoints for experiments 1 and 2 were development (percentage of blastocysts and percentage of blastocysts that were hatching or hatched) and gene expression of the resultant blastocysts.

Experiment $3(\mathrm{n}=15$ replicates $)$ was performed to determine the effect of $0.0(\mathrm{n}=892), 0.004(\mathrm{n}=880)$, $1.3(\mathrm{n}=871)$, and $1.8(\mathrm{n}=898) \mathrm{m} M$ choline chloride on embryo development, blastocyst cell number, and global DNA methylation. The culture medium was BBH7. All replicates were used for measurement of development to the blastocyst stage. Embryos from 5 replicates were used to determine DNA methylation in embryos collected at $3.5 \mathrm{~d}$ after insemination (cell number ranged from 8 to 24 cells; $n=232$ ). Blastocysts harvested $7.5 \mathrm{~d}$ after insemination from another 5 replicates were used to determine DNA methylation ( $\mathrm{n}=$ 204) and cell number $(\mathrm{n}=204)$.

Experiment 4 ( $\mathrm{n}=8$ replicates) was performed to determine the effect of phosphatidylcholine (the most abundant metabolite in plasma) and choline chloride (equivalent to the concentration present during the first week of lactation in Holstein cows) on development. Presumptive zygotes were treated with vehicle only (0.0 $\mathrm{m} M$ choline $\mathrm{n}=605), 1.3 \mathrm{~m} M$ phosphatidylcholine $(\mathrm{n}=617)$, or $0.004 \mathrm{~m} M$ choline chloride $(\mathrm{n}=585)$. The culture medium was BBH7. To solubilize phosphatidylcholine, ethanol was added to all treatments to a final concentration of $0.1 \%$ ( $\mathrm{vol} / \mathrm{vol})$.

\section{Analysis of Gene Expression}

Blastocysts harvested at $7.5 \mathrm{~d}$ postinsemination in experiments 1 and 2 were used to assess gene expression. Blastocysts were washed 3 times in $50-\mu \mathrm{L}$ drops of Dulbecco's PBS (Sigma-Aldrich) containing $0.1 \%$ (wt/vol) polyvinylpyrrolidone (DPBS-PVP; Kodak, Rochester, NY), incubated in $50-\mu \mathrm{L}$ drops containing $0.1 \%$ (wt/vol) protease from Streptococcus griseus (Sigma-Aldrich) in DPBS-PVP for zona pellucida removal, and then washed another 3 times in fresh DPBS-PVP. Subsequently, pools of 10 blastocysts per treatment were transferred into RNase/DNase-free 2-mL tubes, which were plunged into liquid nitrogen and kept at $-80^{\circ} \mathrm{C}$ until analysis.

Samples were subjected to RNA extraction using the Qiagen RNeasy Micro kit (Qiagen, Valencia, CA) 
and following the instructions of the manufacturer. Complementary DNA was produced by using the HighCapacity cDNA Reverse Transcription Kit (Applied Biosystems, Foster City, CA) and following the instructions of the manufacturer. Each sample had a negative control in which reverse transcriptase was omitted and cDNA was stored at $-20^{\circ} \mathrm{C}$.

The analysis of gene expression was performed by using the Fluidigm qPCR microfluidic device Biomark HD system. The PCR primers were designed by Fluidigm Delta Gene assays (Fluidigm Co., San Francisco, CA). Ten genes from experiment 1 and 11 from experiment 2 were removed from the analysis because transcripts were not detectable or the primers did not meet quality control criteria $\left(\mathrm{R}^{2}>0.97\right.$, efficiency 0.8 to 1.3 , and slope between -3.92 and -2.76$)$. A set of 86 primer pairs for experiment 1 (including 3 housekeeping genes) is enriched for genes associated with epigenetic modifications, cellular differentiation (epiblast, hypoblast, and trophoblast), and embryonic development. A set of 85 primer pairs for experiment 2 (including 3 housekeeping genes) is enriched for genes associated with metabolism of choline, lipid transportation, and metabolism of lipids. A description of the lists of genes and the primers for each gene are shown in Supplemental Tables S1 and S2 (https://doi .org/10.3168/jds.2020-18598) for experiments 1 and 2, respectively.

In both experiments, a total of 40 PCR cycles were performed using a 96.96 dynamic array integrated fluidic circuit developed by the manufacturer. The cutoff for detectable genes was those with cycle threshold (Ct) $>27$. The geometric mean was calculated by using Ct values of housekeeping genes $(A C T B, G A P D H$, and HPTR 1 for experiment 1 and $A C T B, R P L 12$, and RPS9 for experiment 2). The geometric mean was used to obtain the delta $\mathrm{Ct}(\mathbf{d C t})$ values of the other genes. Fold changes relative to the geometric mean of the housekeeping genes were then calculated as $2^{-\mathrm{dCt}}$. The $\mathrm{dCt}$ was used for statistical analysis, and fold change values relative to the housekeeping genes are presented in figures.

\section{Global DNA Methylation and Blastocyst Cell Number}

Embryos that were 8 cells or greater (d 3.5 of development) or that were blastocysts (d 7.5 of development) were analyzed for DNA methylation and cell number. Embryos were washed 3 times in DPBS-PVP, fixed in $4 \%$ (wt/vol) paraformaldehyde in DPBS-PVP for $15 \mathrm{~min}$ at room temperature, washed an additional 3 times, and stored for 2 to $3 \mathrm{~d}$ in DPBS-PVP at $4^{\circ} \mathrm{C}$ until the immunolabeling procedure. Fixed embryos were washed 3 times in a wash buffer solution $[0.05 \%$ (vol/vol) Tween 20 in DPBS-PVP] and incubated for $30 \mathrm{~min}$ in $50-\mu \mathrm{L}$ drops of a permeabilization solution $[0.3 \%$ (vol/vol) Triton-X100 in DPBS-PVP]. Embryos were washed 3 times in wash buffer and incubated for 1 $\mathrm{h}$ at $37^{\circ} \mathrm{C}$ in the dark in $50-\mu \mathrm{L}$ drops containing $50 \mu \mathrm{g} /$ $\mathrm{mL}$ RNase A (Qiagen) in DPBS-PVP. Embryos were washed 3 times and incubated for $30 \mathrm{~min}$ at $37^{\circ} \mathrm{C}$ in the dark in $3 \mathrm{M} \mathrm{HCl}$ and $0.2 \%$ (wt/vol) PVP, washed 3 times in wash buffer, and incubated for $10 \mathrm{~min}$ in $100 \mathrm{~m} M$ Tris, $\mathrm{pH} 8.5$ containing $0.2 \%$ (wt/vol) PVP. Embryos were washed 3 times and incubated overnight at $4^{\circ} \mathrm{C}$ in blocking buffer $[5 \%(\mathrm{wt} / \mathrm{vol}) \mathrm{BSA}$ fraction $\mathrm{V}$ in DPBS-PVP].

Subsequently, embryos were washed 3 times and incubated for $1 \mathrm{~h}$ in the dark at room temperature in $50-\mu \mathrm{L}$ drops containing $1 \mu \mathrm{g} / \mathrm{mL}$ primary antibody (affinitypurified mouse monoclonal anti-5-methylcytosine; Calbiochem, Darmstadt, Germany) in blocking buffer solution. For each run, one embryo was used as a negative control, which was incubated in $1 \mu \mathrm{g} / \mathrm{mL}$ mouse $\operatorname{IgG}$ (Sigma-Aldrich) instead of anti-5-methylcytosine. All embryos were washed 3 times and incubated for $1 \mathrm{~h}$ in the dark at room temperature in $50-\mu \mathrm{L}$ drops containing $2 \mu \mathrm{g} / \mathrm{mL}$ secondary antibody (Alexa Fluor Goat anti-Mouse 488; Invitrogen-Thermo Fisher Scientific, Waltham, MA) in blocking buffer solution.

Embryos were washed 3 times in wash buffer and then incubated for $15 \mathrm{~min}$ in the dark at room temperature in $50-\mu \mathrm{L}$ drops containing $50 \mu \mathrm{g} / \mathrm{mL}$ propidium iodide (Sigma-Aldrich) in DPBS-PVP. Embryos were then mounted onto slides containing $7 \mu \mathrm{L}$ of Slow Fade (Invitrogen-Thermo Fisher Scientific) and covered with a coverslip.

Slides were examined with an epifluorescence microscope (Zeiss Axio Plan 2, Göttingen, Germany) using a $40 \times$ objective. The fluorescein isothiocyanate and rhodamine filter exposure times were constant for all embryos analyzed in an individual replicate. The images were obtained with a digital camera (Zeiss AxioCam $\mathrm{MRm}$, Zeiss) and saved in zvi format (AxioVision software, Zeiss) for further analysis using ImageJ software (version 1.60_41, National Institutes of Health, Washington, DC). For embryos at $3.5 \mathrm{~d}$ of development, fluorescence intensity of 5-methylcytosine and propidium iodide was evaluated by encircling individual nuclei of cells. For blastocysts, fluorescence intensity of 5 -methylcytosine and propidium iodide was evaluated by encircling the whole blastocyst. For both embryos at d 3.5 and blastocysts, intensity of labeling for DNA methylation was calculated as the ratio of fluorescent intensity for 5 -methylcytosone divided by fluorescent intensity for propidium iodide. Blastocyst cell number was estimated based on the number of nuclei labeled with propidium iodide. 


\section{Statistical Analysis}

Data on the percentage of presumptive zygotes that cleaved, percentage of presumptive zygotes that developed to blastocyst stage, percentage of cleaved embryos that developed to blastocyst stage, and percentage of blastocysts that were hatching or hatched were analyzed by logistic regression fitted to a binomial distribution using the GLIMMIX procedure of the Statistical Analysis System version 9.4 (SAS Institute, Cary, NC). For experiments 1,3 , and 4 , the model included fixed effect of choline treatment and random effect of replicate. For experiment 2, the model included the fixed effects of choline treatment, culture medium, and interaction of choline concentration with culture medium; replicate was also included as a random effect.

Data on gene expression, global DNA methylation intensity, and embryo cell number were evaluated by ANOVA using the GLM procedure of SAS. For delta $\mathrm{Ct}$ values, the model included the fixed effect of choline treatment. For DNA methylation of 3.5-d embryos, each embryo was classified by stage of development as slow ( $<15$ cells) or fast ( $\geq 15$ cells). The value of 15 cells was chosen because it represents the third quartile of cell stage distribution. The statistical model included the fixed effects of treatment, stage, and the interaction of treatment with stage and the random effect of replicate. For DNA methylation of blastocysts, the model included the fixed effects of choline treatment and the random effect of replicate. For embryo cell number, the model included the fixed effect of treatment and random effect of replicate. In all cases, differences between means for individual choline treatments were evaluated by Fisher's least significant difference using the LSmeans procedure of SAS and those differences with $P$ $\leq 0.05$ reported.

\section{RESULTS}

\section{Cleavage and Development to the Blastocyst Stage}

A total of 4 experiments were conducted. For experiment 1 , in which embryos were cultured with $0,1.3,1.8$, and $6.37 \mathrm{mM}$ choline chloride, there were no significant effects of choline treatment on the percentage of presumptive zygotes that cleaved after fertilization (Figure 1A), the percentage of cleaved embryos (Figure 1B) or presumptive zygotes (Figure 1C) becoming blastocysts, or the percentage of blastocysts that were hatching and hatched (Figure 1D). Experiment 2 was performed to determine whether the effect of addition of $1.3 \mathrm{mM}$ choline chloride depends on culture medium. Results are presented in Figure 2. Although the percentage of cleaved embryos becoming blastocysts $(P=0.0562)$, zygotes becoming blastocysts $(P=0.0552)$, and blastocysts hatching and hatched $(P=0.0529)$ tended to be greater for BBH7 than SOF-BE2, we observed no effects of choline chloride treatment or interaction of choline chloride with culture medium on any measure of development.

The effects of $0.004,1.3$, and $1.8 \mathrm{~m} M$ choline chloride were examined in experiment 3 . Choline chloride concentration had no effect on the percentage of zygotes that cleaved after fertilization (Figure 3A) or the percentage of presumptive zygotes becoming blastocysts (Figure 3C). A tendency was observed for the percentage of cleaved embryos becoming blastocysts to be affected by treatment $(P=0.0626)$. The mean separation test was indicative that more cleaved embryos treated with $0.004 \mathrm{~m} M$ choline chloride became blastocysts $(P$ $<0.05$ ) than cleaved embryos treated with $0.0 \mathrm{~m} M$ choline chloride (Figure 3B). Treatment also affected the percentage of blastocysts that were hatching or hatched $(P=0.0004)$; results of the mean separation test were indicative that more blastocysts cultured with 0.004 $\mathrm{m} M$ choline chloride were hatching or hatched than for other treatments (Figure 3D).

Experiment 4 was performed to determine the effect of phosphatidylcholine (the most abundant choline metabolite in blood plasma) and free choline on embryonic development when added at concentrations similar to those in blood plasma during the first week of lactation in Holstein cows. Treatment had no effect on the percentage of presumptive zygotes that cleaved after fertilization (Figure 4A). However, the percentage of cleaved embryos $(P=0.0014)$ and presumptive zygotes $(P=0.0005)$ becoming blastocysts was lower for embryos exposed to $1.3 \mathrm{mM}$ phosphatidylcholine than embryos treated with 0.0 or $0.004 \mathrm{~m} M$ choline chloride (Figure $4 \mathrm{~B}$ and $4 \mathrm{C}$ ). Unlike for experiment 3, treatment of embryos with $0.004 \mathrm{mM}$ choline chloride did not affect the percentage of cleaved embryos becoming blastocysts (Figure 4B). However, like for experiment 3 , treatment affected the percentage of blastocysts that were hatching or hatched $(P=0.0140)$. In particular, a higher percentage of blastocysts cultured with 0.004 $\mathrm{m} M$ choline chloride was hatching or hatched $(P<$ $0.05)$ than embryos treated with $0.0 \mathrm{~m} M$ choline chloride (Figure 4D).

\section{Gene Expression}

Results for the effect of choline on gene expression of blastocysts in experiment 1 are shown in Figure 5. A total of 10 of the 83 genes analyzed were affected $(P<$ 0.05 ) by choline chloride concentration. In each case, gene expression was highest for blastocysts derived from embryos treated with $1.3 \mathrm{~m} M$ choline chloride 

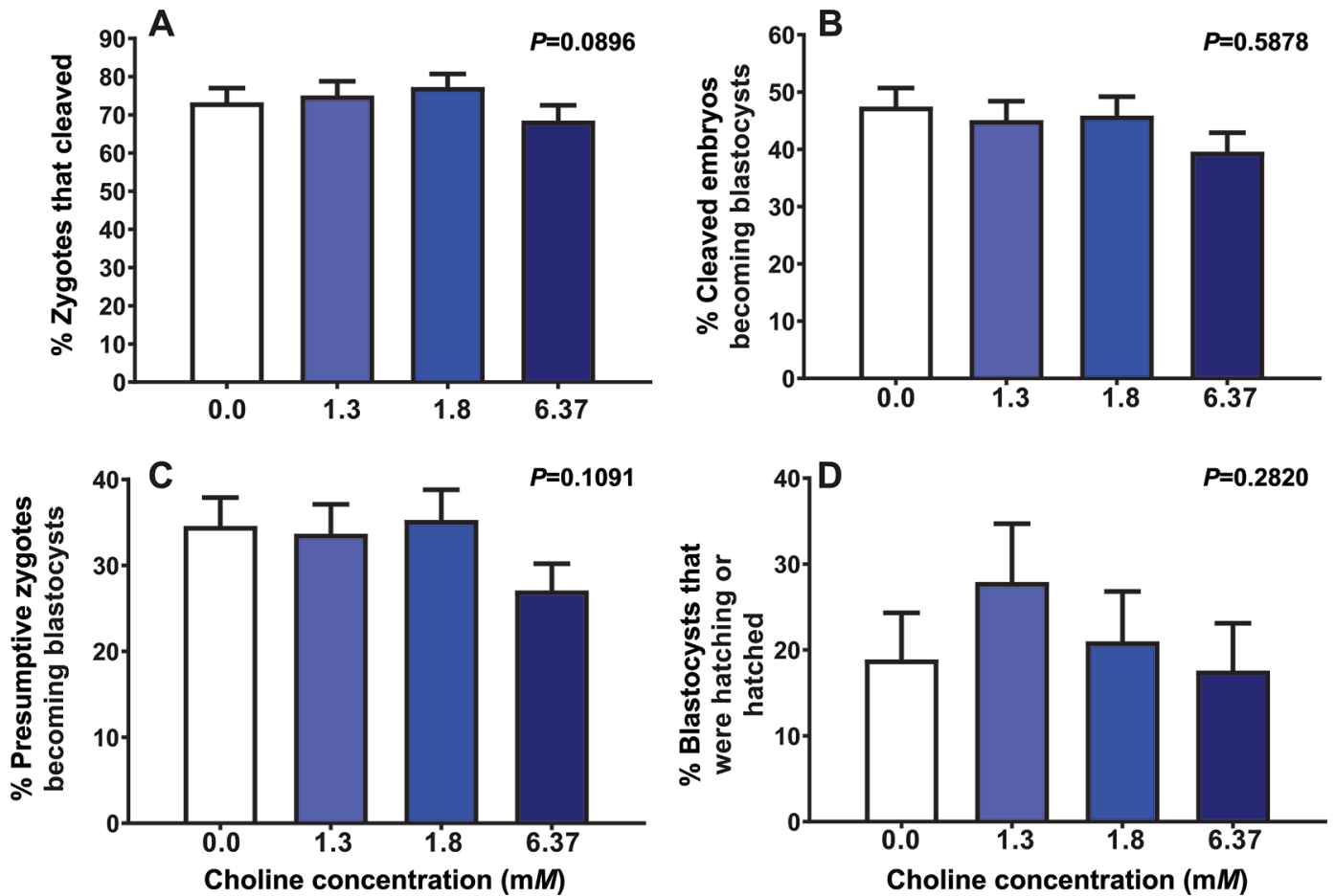

Figure 1. Effect of concentrations of choline chloride in culture medium ranging from 1.3 to $6.37 \mathrm{~m} M$ on the percentage of zygotes that cleaved after fertilization (A), percentage of cleaved embryos that became a blastocyst (B), percentage of zygotes that became a blastocyst (C), and percentage of blastocysts that were hatching or had hatched (D). Data are presented as LSM \pm SEM. The $P$-value for the main effect of choline concentration is shown in each graph.
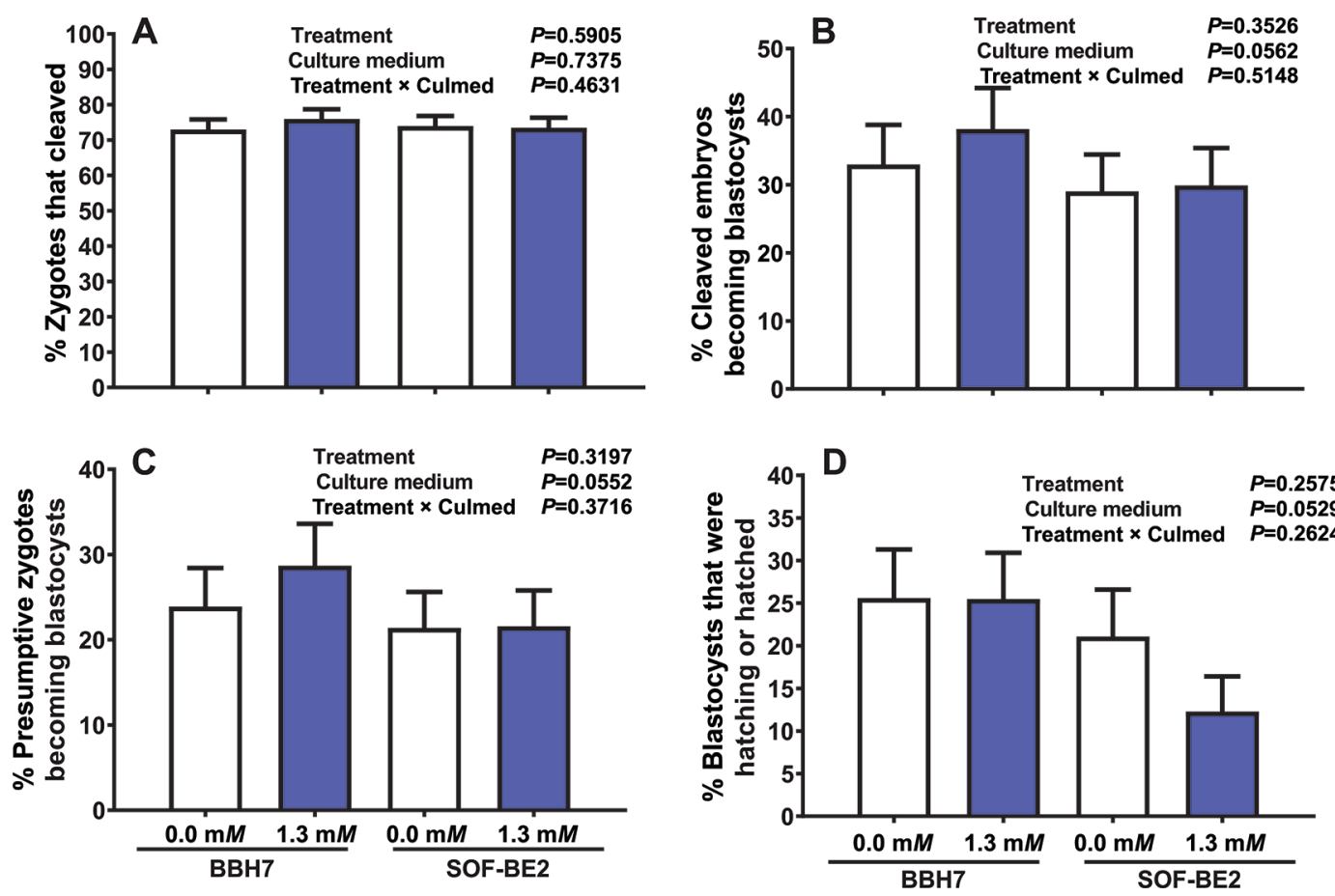

Figure 2. Interaction between culture medium (Culmed) and treatment with $1.3 \mathrm{~m} M$ choline chloride on the percentage of zygotes that cleaved after fertilization (A), percentage of cleaved embryos that became a blastocyst (B), percentage of zygotes that became a blastocyst (C), and percentage of blastocysts that were hatching or had hatched (D). Data are presented as LSM \pm SEM. The $P$-values for main effects and interactions are shown in each graph. The culture medium was either BBH7 or synthetic oviduct fluid-bovine embryo 2 (SOF-BE2). 
than for other treatments. This was true for $A M O T$, HDAC8, HNF4A, KDM2B, MBNL3, NANOG, SAV1, SOX2, STAT1, and STAT3.

For experiment 2, only 2 genes (ASS1 and GPAM) of 82 genes evaluated were affected by choline $(P<$ $0.05)$ and no interaction was observed for choline treatment and culture medium. Gene expression of $A S S 1$ was lower for embryos treated with choline with respect to control (fold change relative to housekeeping genes: $0.003 \pm 0.07$ vs. $0.023 \pm 0.07$ ) and expression of GPAM was higher for embryos treated with choline as compared with control (fold change relative to housekeeping genes: $0.032 \pm 0.01$ vs. $0.010 \pm 0.01$ ).

\section{Global DNA Methylation and Blastocyst Cell Number}

Representative images of labeling for DNA methylation are shown in Figure 6. As expected, labeling for 5-methylcytosine was limited to nuclei. Results for quantification of global DNA methylation and blastocyst cell number are shown in Figure 7. For d-3.5 embryos (Figure 7A), labeling for DNA methylation was affected by choline treatment $(P=0.0039)$ and stage of development $(P=0.0302)$ but not by the interaction. The DNA methylation was lower for embryos treated with $1.3 \mathrm{~m} M$ choline chloride than for embryos of other treatments, and DNA methylation was lower for embryos with slow development $(<15$ cells) than for embryos with fast development $(\geq 15$ cells). Choline did not affect the number of cells at d $3.5(P=0.7596)$. Least squares means \pm standard error of the mean were $11.9 \pm 0.47,12.6 \pm 0.47,12.3 \pm 0.56$, and $12.2 \pm 0.50$ for $0,0.004,1.3$, and $1.8 \mathrm{~m} M$ choline chloride, respectively.

Choline treatment affected DNA methylation (Figure 7B) in blastocysts $(P<0.0001)$. Intensity of labeling for DNA methylation was higher for embryos treated with 1.3 and $1.8 \mathrm{~m} M$ choline chloride as compared with embryos treated without choline. Choline treatment also affected blastocyst cell number $(P=0.0080)$. The total number of cells was higher for embryos treated with $0.004 \mathrm{~m} M$ choline chloride compared with embryos treated with $0.0,1.3$, or $1.8 \mathrm{~m} M$ choline chloride (Figure 7C).

\section{DISCUSSION}

The main purpose of the experiments was to use the embryo produced in vitro as a model to evaluate whether feeding RPC, which has been reported to improve
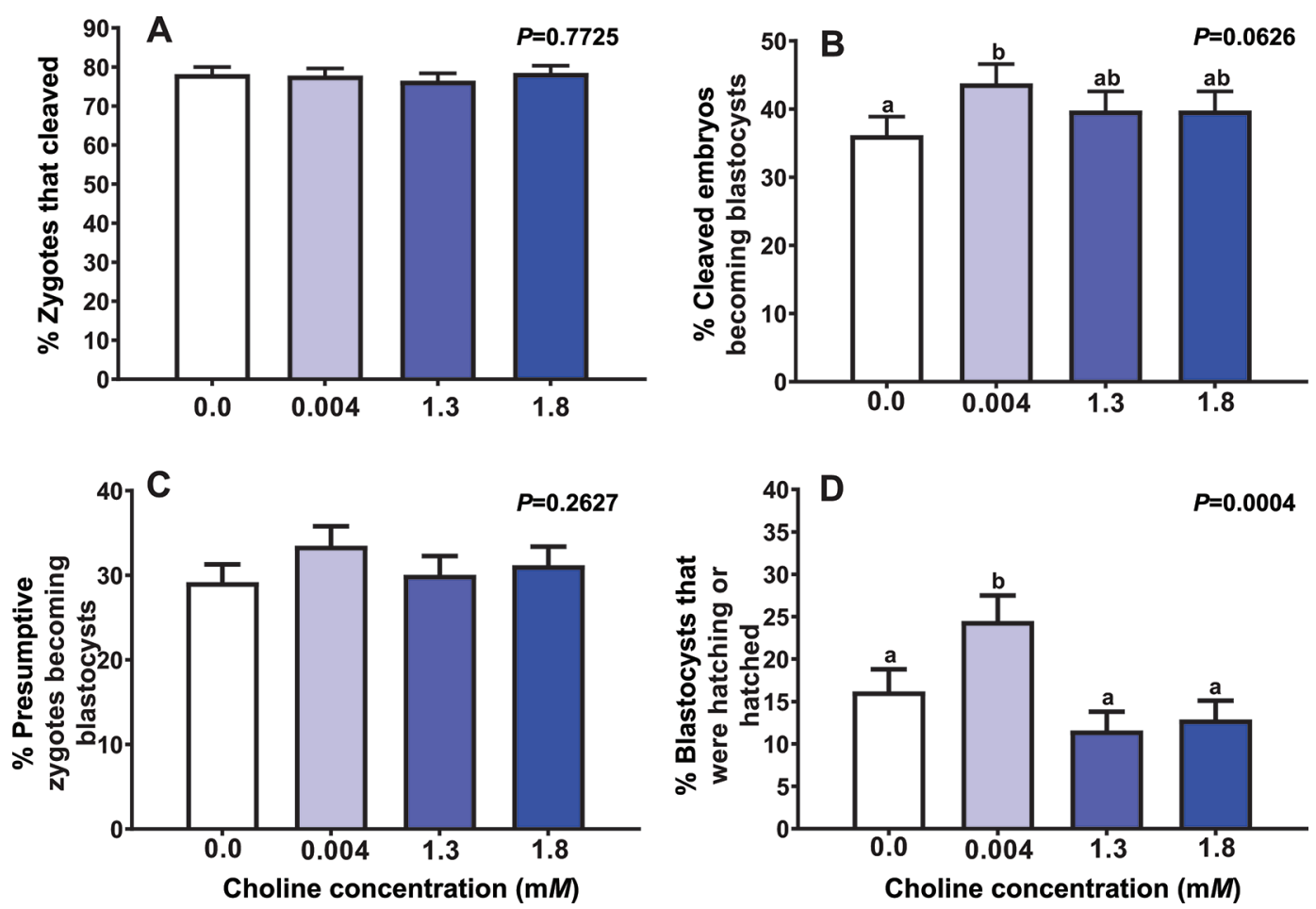

Figure 3. Effect of concentrations of choline chloride in culture medium ranging from 0.004 to $1.8 \mathrm{~m} M$ on the percentage of zygotes that cleaved after fertilization (A), percentage of cleaved embryos that became a blastocyst (B), percentage of zygotes that became a blastocyst (C), and percentage of blastocysts that were hatching or had hatched (D). Data are presented as LSM \pm SEM. The $P$-value for main effect of choline concentration is shown in each graph. Treatment means that differ from each other at $P<0.05$ as determined by Fisher's least significance difference are indicated by the different letters $(\mathrm{a}, \mathrm{b})$ over each bar. 
reproductive outcomes in dairy cows (Scheer-Oelrichs, 2003; Ardalan et al., 2010; Zenobi et al., 2018a), can affect the phenotype of the embryo through provision of choline chloride. Results indicated that choline chloride had concentration-dependent effects on competence of embryos to develop to the blastocyst stage and on stage of the resultant blastocysts as well as on gene expression and DNA methylation. Thus, it is possible that feeding RPC could alter the characteristics of the preimplantation embryo by increasing choline availability to the embryo. These results also have implications for the production of embryos in vitro because choline is not typically added to defined culture medium used to culture embryos.

As will be discussed below, low concentrations of choline had different actions on the embryo than high concentrations and more work is needed to understand which of the concentrations tested here is most relevant to the embryo developing in utero. The lowest concentration of choline chloride tested $(0.004 \mathrm{mM})$ was generally positive for competence of the embryo to develop to the blastocyst stage, higher concentrations $(1.3,1.8$, and $6.37 \mathrm{mM})$ were without effect, and the choline derivative, phosphatidylcholine, was inhibitory at the only concentration tested $(1.3 \mathrm{mM})$. In contrast to effects on development, effects of choline chloride on gene expression and DNA methylation were of highest magnitude at a concentration of $1.3 \mathrm{~m} M$. Effects were either not observed or of lower magnitude at concentrations of 1.8 or $6.37 \mathrm{~m} M$.

In experiment 3 , treatment with $0.004 \mathrm{~m} M$ choline chloride increased the percentage of cleaved embryos becoming blastocysts, the percentage of blastocysts that were hatching or hatched, and the total number of cells in the blastocyst. In experiment 4, involving fewer replicates, $0.004 \mathrm{mM}$ choline chloride had no effect on development to the blastocyst stage and the total number of cells in the blastocyst was not evaluated. However, the percentage of blastocysts that were hatching and hatched was again increased for those produced in medium containing $0.004 \mathrm{~m} M$ choline chloride. This positive effect of choline chloride is likely to be physiologically relevant. Concentrations of free choline in plasma of lactating Holstein cows range from 0.0030 to $0.0045 \mathrm{~m} M$ (Artegoitia et al., 2014) and the concentration used here $(0.004 \mathrm{mM})$ approximates the concentrations observed early postpartum (Artegoitia et al., 2014). Concentrations of free choline are also abundant in uterine fluid as detected by MS during the first $7 \mathrm{~d}$ after ovulation (Tríbulo et al., 2019a), but the absolute concentrations are not known. Understanding actions of choline and its metabolites at physiologically
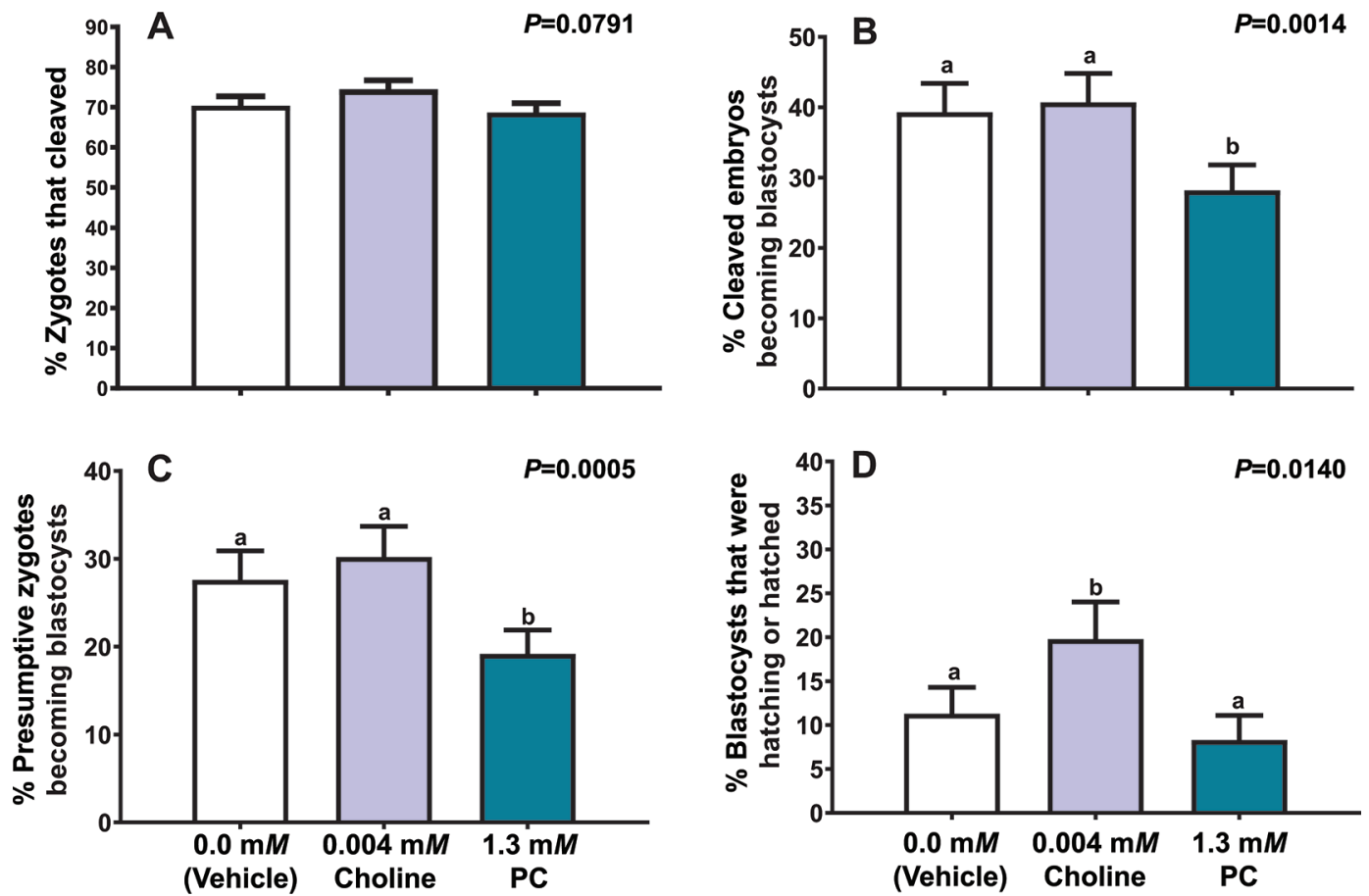

Figure 4. Effect of $0.004 \mathrm{~m} M$ choline chloride (choline) or $1.3 \mathrm{~m} M$ phosphatidylcholine (PC) in culture medium on the percentage of zygotes that cleaved after fertilization (A), percentage of cleaved embryos that became a blastocyst (B), percentage of zygotes that became a blastocyst (C), and percentage of blastocysts that were hatching or had hatched (D). Data are presented as LSM \pm SEM. The $P$-value for main effect of treatment is shown in each graph. Treatment means that differ from each other at $P<0.05$ as determined by Fisher's least significance difference are indicated by the different letters $(\mathrm{a}, \mathrm{b})$ over each bar. 
relevant concentrations will require a better idea of concentrations of all choline metabolites in uterine fluid at the time cows are ordinarily inseminated and how feeding RPC changes those concentrations.
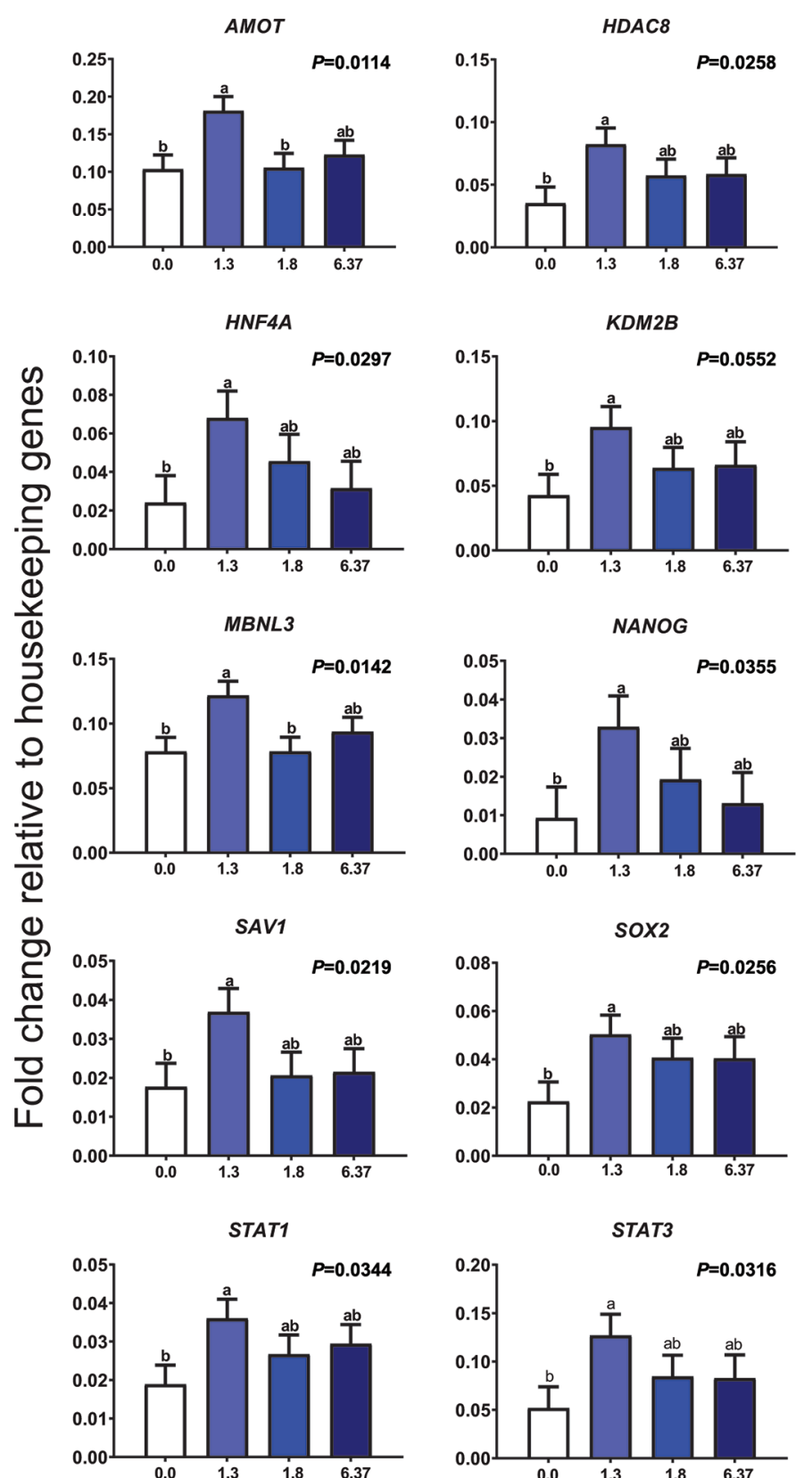

\section{Choline concentration ( $\mathrm{mM}$ )}

Figure 5. Effect of different concentrations of choline chloride in the culture medium on expression of specific genes in blastocysts (experiment 1). Data are presented as LSM \pm SEM. The $P$-value for the effect of choline concentration is shown in each graph. Treatment means that differ from each other at $P<0.05$ as determined by Fisher's least significance difference are indicated by the different letters $(a, b)$ over each bar.
A negative effect on embryo development was observed when phosphatidylcholine was added to culture medium. Phosphatidylcholine is the main metabolite in blood plasma of cows and ranges in concentration from 1.0 to $13.5 \mathrm{~m} M$ during lactation (Artegoitia et al., 2014). Many types of phosphatidylcholine species have been found in blood plasma (Artegoitia et al., 2014) and uterine fluid (Belaz et al., 2016). For the current experiment, we used a molecule derived from soybean. More research should be performed to explore whether the negative result observed in our study is associated with the concentration, type, or source of phosphatidylcholine used. Understanding the effect of feeding RPC on embryonic development will require determination of how feeding alters concentrations of choline and its metabolites such as phosphatidylcholine in the uterine lumen.

No effect was observed of $1.3,1.8$, or $6.37 \mathrm{~m} M$ choline chloride on developmental endpoints. It is most likely that high concentrations of choline chloride activate other mechanisms in the embryo that counteract the pro-developmental benefits of low concentrations of choline chloride. These effects could be the result of direct effects of choline chloride or one of its metabolites. The lack of effect of high concentrations of choline chloride on development does not mean the embryo is not being affected. In fact, choline can regulate the physiology of the embryo at higher concentrations as indicated by observations that gene expression and DNA methylation were affected by higher concentrations of choline chloride. Effects were most pronounced at $1.3 \mathrm{~m} M$. This concentration represents the sum of concentrations of all choline metabolites in plasma at 7 DIM. Treatment of embryos with a higher concentration, $1.8 \mathrm{mM}$ (representative of the expected sum of concentrations of all choline metabolites in cows fed $\mathrm{RPC})$, did not change gene expression and caused less pronounced effects on DNA methylation than did 1.3 $\mathrm{m} M$ choline chloride. The dose response of embryos to choline chloride may reflect the capacity of choline transporters or kinetics of enzymes that metabolize choline. Saturation of transporters or enzymes may prevent a linear response to choline. In concordance with this idea, a nonlinear response has been observed in the cellular uptake of choline (Iwao et al., 2016) and activity of choline enzymes (Lee et al., 2012).

Genes found to be upregulated in blastocysts that developed in medium with $1.3 \mathrm{~m} M$ choline chloride (experiment 1 and Figure 5) play important roles in epigenetic regulation and differentiation of the blastocyst. HDAC8 encodes for a histone deacetylase enzyme and KDM2B encodes for a lysine demethylase enzyme (Hosseini et al., 2015). Two genes, AMOT and SAV1, encode for proteins involved in Hippo signaling. In 
bovine embryos, AMOT is important for formation of trophectoderm cells and knockdown of AMOT reduces the number of cells positive to CDX2 (Negrón-Pérez and Hansen, 2018). Two genes, NANOG and SOX2, encode for transcription factors involved in the maintenance of pluripotency and predominant on inner cell mass (ICM; Negrón-Pérez et al., 2017). The HNF4A gene encodes for a transcription factor involved in glucose homeostasis (Cagnone and Sirard, 2016) and is predominantly found in epiblasts and hypoblasts (Negrón-Pérez et al., 2017). The MBNL3 gene encodes for a protein related to muscle differentiation during early development (Lee et al., 2007) and is expressed in all cell types in blastocysts but mainly in hypoblast (Negrón-Pérez et al., 2017). The STAT1 and STAT3 genes encode for proteins which mediate response to cytokines. In fact, STAT3 is a mediator for actions of IL-6 to increase number of ICM cells (Wooldridge et al., 2019) and is involved in maintenance of pluripotency in ICM (Do et al., 2013).

Only 2 genes were significantly influenced by choline chloride in blastocysts from the list of genes associated with lipid transportation, lipid, and choline metabolism in experiment 2. Specifically, expression of ASS1 was reduced by $1.3 \mathrm{mM}$ choline chloride. This gene encodes for an enzyme involved in nitrogen metabolism and synthesis of arginine. The expression of GPAM was increased by choline chloride. This gene codes for an enzyme that catalyzes the initial step of glycerolipid synthesis and is considered a pivotal player in the regu- lation of cellular triacylglycerol and phospholipid levels (Yu et al., 2017). Surprisingly, no genes involved in choline metabolism were altered at the blastocyst stage by choline chloride. It is possible that choline treatment affects activity of enzymes involved in choline metabolism during early embryonic development but that such effects are reversed by the blastocyst stage. Choline was added to the culture medium at the beginning of embryo culture (15-16 h postfertilization).

Global DNA methylation of blastocysts was increased by $1.3 \mathrm{~m} M$ choline chloride, and to a much lesser extent, $1.8 \mathrm{mM}$. Choline can give rise to $\mathrm{S}$ adenosylmethionine, the universal methyl donor for DNA methylation (Zeisel, 2017). An increase in DNA methylation of bovine embryos produced in vitro has also been observed when culture medium was supplemented with other molecules involved in one-carbon metabolism including homocysteine (Ikeda et al., 2010) and S-adenosylmethionine (Shojaei Saadi et al., 2016).

Given the role of choline as a methyl donor, it was surprising to observe that treatment of embryos with $1.3 \mathrm{~m} M$ choline chloride reduced DNA methylation in embryos at d 3.5 after fertilization, when embryos ranged in cell number from 8 to 24 cells. Although the decrease in DNA methylation at d 3.5 was unexpected, there are precedents. Morula- and blastocyst-stage embryos recovered from cows fed rumen-protected methionine and RPC had less intense labeling for DNA methylation than control embryos (Acosta et al., 2016). At d 3.5 of development, the embryo is transitioning
Embryos

$3.5 \mathrm{~d}$
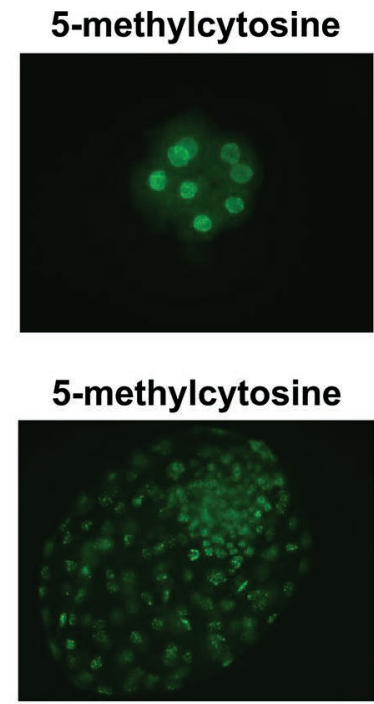

Blastocysts $7.5 \mathrm{~d}$
Propidium iodide
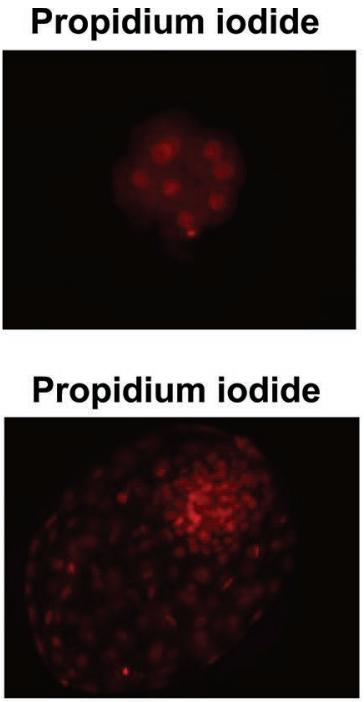

Choline chloride $0.0 \mathrm{mM}$
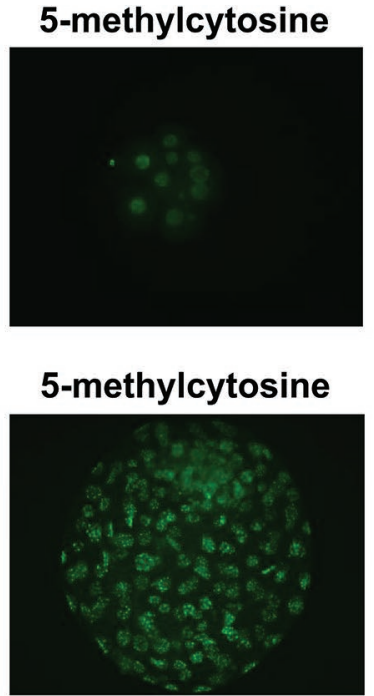

Propidium iodide

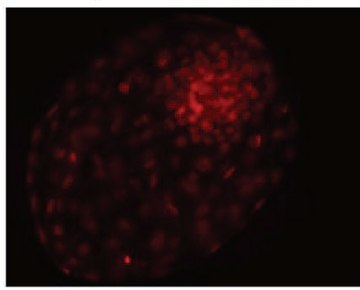

Choline chloride $1.3 \mathrm{mM}$

Figure 6. Representative images of embryos collected at d 3.5 (cell number ranged from 8 to 24 cells) and blastocysts collected at d 7.5 postfertilization. Embryos were treated with 0.0 or $1.3 \mathrm{~m} M$ choline chloride and immunolabeled with 5 -methylcytosine (green) and propidium iodide (red). 
from a period characterized by removal of DNA methylation, with a nadir in DNA methylation at about the 8-cell stage (Dobbs et al., 2013; Jiang et al., 2018), to one where DNA methylation increases. Perhaps, high concentrations of choline or its metabolites activate pathways that facilitate DNA demethylation or inhibit de novo methylation. For example, choline chloride could conceivably regulate choline kinase activity, which is involved in several signaling pathways including that of phosphatidylinositol 3 kinase (PI3K; Clem et al., 2011), that in turn can induce dissociation of DNA methyltransferase 1 from chromatin and cause hypomethylation (Spangle et al., 2017).

The fact that choline chloride increased DNA methylation in blastocysts but decreased it in embryos that were 8 to 24 cells in number is an indication that choline chloride functions in the embryo in more ways than just as a methyl donor. Effects of choline chloride described in this paper could be the result of actions of choline itself or of metabolites of choline functioning in various roles including cell signaling. Choline is a precursor of the neurotransmitter acetylcholine, phosphatidylcholine, and the methyl donor betaine. Transcripts coding for enzymes involved in the synthesis of each of these choline derivatives are present during the preimplantation period in bovine embryos (Ikeda et al., 2010; Jiang et al., 2014). Evidence indicates that these pathways are important for preimplantation development. In mice, addition of acetylcholine to culture medium rescues embryos from the 2-cell block to development to the blastocyst stage (Cho et al., 2009). Knockout of the gene for choline kinase (the first enzyme in the pathway for synthesis of phosphatidylcholine) causes embryo lethality between d 3.5 and 7.5 of development in mice (Wu et al., 2008). Reduction of choline kinase activity (based on concentrations of ${ }^{14} \mathrm{C}$-labeled choline and downstream levels of choline metabolites) alters mitogen-activated protein kinase and PI3K signaling in HeLa cells (Clem et al., 2011). Knockdown of betaine-homocysteine methyltransferase (which removes methyl groups from betaine) decreases the proportion of embryos developing to the blastocyst stage and reduces the number of ICM cells in blastocysts (Lee et al., 2012). Products of phosphatidylcholine metabolism can function to regulate transcription through binding to peroxisome proliferator-activated receptor- $\alpha$ (Chakravarthy et al., 2009). Phosphatidylcholine has also been implicated in insulin signaling (van der Veen et al., 2019) as well as cell proliferation and death (Ridgway, 2013). The extensive and diverse involvement of choline in cellular processes means that more research to elucidate pathways by which both low and high concentrations of choline chloride modify embryonic function is warranted.
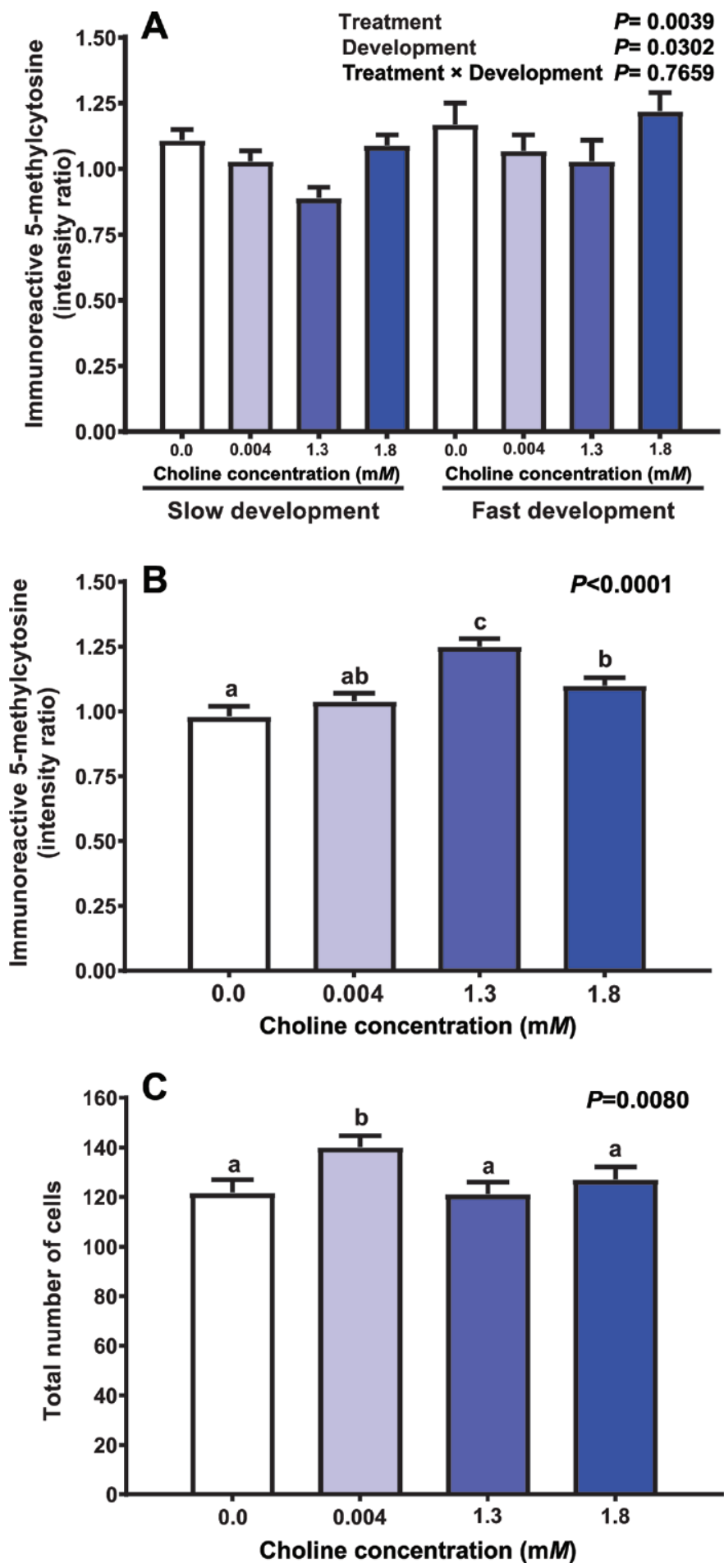

Figure 7. Effect of different concentrations of choline chloride in the culture medium (experiment 4) on DNA methylation of 3.5-d embryos with slow ( $<15$ cells) and fast ( $\geq 15$ cells) development (A), DNA methylation in blastocysts (B), and blastocyst cell number (C). Data are presented as LSM $\pm \mathrm{SEM}$. The $P$-value for the effect of choline concentration is shown in each graph. For panel A, $1.3 \mathrm{~m} M$ was different from $0 \mathrm{mM}(P=0.0044)$ as determined by Fisher's least significant difference. For panels B and $\mathrm{C}$, treatment means that differ from each other at $P<0.05$ as determined by Fisher's least significance difference are indicated by the different letters $(\mathrm{a}-\mathrm{c})$ over each bar. 
Feeding RPC caused changes in plasma concentrations of total phosphatidylcholines, total lysophosphatidylcholines, and sphingomyelin but did not affect concentrations of water-soluble derivatives of choline such as choline and betaine (Zenobi et al., 2018b). Another important question, therefore, is elucidation of the consequences of feeding RPC for availability of choline and its metabolites to the developing embryo. As stated before, choline and its metabolites are present in uterine fluid (Belaz et al., 2016; Tríbulo et al., 2019a), but it is not known how feeding RPC changes concentrations of these molecules in the oviduct or uterus. Given choline's role as a methyl donor, it will also be instructive to determine to what extent other methyl donors exert similar effects on embryonic development and physiology. Feeding rumen-protected methionine, for example, changed gene expression in the bovine blastocyst (Peñagaricano et al., 2013).

In conclusion, addition of choline to culture medium alters the phenotype of preimplantation bovine embryos produced in vitro. Choline chloride can act in a concentration-dependent manner to alter development, expression of specific genes, and DNA methylation.

\section{ACKNOWLEDGMENTS}

Research was supported by the L.E. "Red" Larson Endowment, a gift from Balchem Corporation (New Hampton, NY) and funding for E. Estrada-Cortés by CONACyT-México. The authors acknowledge Eddie Cummings for ovary collection and owners of Florida Beef Inc. (Zolfo Springs, FL) for providing ovaries. We also gratefully acknowledge performance of Fluidigm PCR analysis by Lesley de Armas and the Miami Center for AIDS Research (CFAR) at the University of Miami Miller School of Medicine (Miami, FL), which is funded by a grant (P30AI073961) from the National Institutes of Health. Thanks are also extended to James Moss, Elizabeth Jannaman, and students in the laboratory of Peter Hansen for technical assistance. Conflict of interest: PJH is a co-owner of Cooley Biotech LLC, manufacturer of BBH7 culture medium. The other authors have not stated any conflicts of interest.

\section{REFERENCES}

Acosta, D. A. V., A. C. Denicol, P. Tríbulo, M. I. Rivelli, C. Skenandore, Z. Zhou, D. Luchini, M. N. Corrêa, P. J. Hansen, and F. C. Cardoso. 2016. Effects of rumen-protected methionine and choline supplementation on the preimplantation embryo in Holstein cows. Theriogenology 85:1669-1679. https://doi.org/10.1016/j .theriogenology.2016.01.024.

Ardalan, M., K. Rezayazdi, and M. Dehghan-Banadaky. 2010. Effect of rumen-protected choline and methionine on physiological and metabolic disorders and reproductive indices of dairy cows. J.
Anim. Physiol. Anim. Nutr. (Berl.) 94:e259-e265. https://doi.org/ 10.1111/j.1439-0396.2009.00966.x.

Aréchiga, C. F., S. Vázquez-Flores, O. Ortíz, J. Hernández-Cerón, A. Porras, L. R. McDowell, and P. J. Hansen. 1998. Effect of injection of $\beta$-carotene or vitamin $\mathrm{E}$ and selenium on fertility of lactating dairy cows. Theriogenology 50:65-76. https://doi.org/10.1016/ S0093-691X(98)00114-9.

Artegoitia, V. M., J. L. Middleton, F. M. Harte, S. R. Campagna, and M. J. de Veth. 2014. Choline and choline metabolite patterns and associations in blood and milk during lactation in dairy cows. PLoS One 9:e103412. https://doi.org/10.1371/journal.pone .0103412 .

Belaz, K. R., A. Tata, A. Franca, M. R. Santos da Silva, M. I. Vendramini, P. H. Fernandes, A. M. A. P. D'Alexandri, and F. L. Eberlin. 2016. Phospholipid profile and distribution in the receptive oviduct and uterus during early diestrus in cattle. Biol. Reprod. 95:127. https://doi.org/10.1095/biolreprod.116.142257.

Block, J., L. Bonilla, and P. J. Hansen. 2010. Efficacy of in vitro embryo transfer in lactating dairy cows using fresh or vitrified embryos produced in a novel embryo culture medium. J. Dairy Sci. 93:5234-5242. https://doi.org/10.3168/jds.2010-3443.

Bonilla, L., D. Luchini, E. Devillard, and P. J. Hansen. 2010. Methionine requirements for the preimplantation bovine embryo. J. Reprod. Dev. 56:527-532. https://doi.org/10.1262/jrd.10-037H.

Butler, W. R. 2000. Nutritional interactions with reproductive performance in dairy cattle. Anim. Reprod. Sci. 60-61:449-457. https:// doi.org/10.1016/S0378-4320(00)00076-2.

Cagnone, G., and M. A. Sirard. 2016. The embryonic stress response to in vitro culture: Insight from genomic analysis. Reproduction 152:R247-R261. https://doi.org/10.1530/REP-16-0391.

Chakravarthy, M. V., I. J. Lodhi, L. Yin, R. R. V. Malapaka, H E. Xu, J. Turk, and C. F. Semenkovich. 2009. Identification of a physiologically relevant endogenous ligand for PPAR $\alpha$ in liver. Cell 138:476-488. https://doi.org/10.1016/j.cell.2009.05.036.

Cho, S. K., S. Y. Yoon, C. G. Hur, H. Y. Yang, Ch. Choe, E. J. Kim, J. S. Joo, K. R. Kang, J. Y. Park, S. G. Hong, J. Han, and D. Kang. 2009. Acetylcholine rescues two-cell block through activation of IP3 receptors and Ca2+/calmodulin-dependent kinase II in an ICR mouse strain. Pflugers Arch. 458:1125-1136. https://doi .org/10.1007/s00424-009-0686-7.

Clem, B. F., A. L. Clem, A. Yalcin, U. Goswami, S. Arumugam, S. Telang, J. O. Trent, and J. Chesney. 2011. A novel small molecule antagonist of choline kinase- $\alpha$ that simultaneously suppresses MAPK and PI3K/AKT signaling. Oncogene 30:3370-3380. https: //doi.org/10.1038/onc.2011.51.

Do, D. V., J. Ueda, D. M. Messerschmidt, Ch. Lorthongpanich, Y. Zhou, B. Feng, G. Guo, P. J. Lin, M. Z. Hossain, W. Zhang, A. Moh, Q. Wu, P. Robson, H. H. Ng, L. Poellinger, B. B. Knowles, D. Solter, and Y. Y. Fu. 2013. A genetic and developmental pathway from STAT3 to the OCT4-NANOG circuit is essential for maintenance of ICM lineages in vivo. Genes Dev. 27:1378-1390. https://doi.org/10.1101/gad.221176.113.

Dobbs, K. B., M. Rodriguez, M. J. Sudano, M. S. Ortega, and P. J. Hansen. 2013. Dynamics of DNA methylation during early development of the preimplantation bovine embryo. PLoS One 8:e66230. https://doi.org/10.1371/journal.pone.0066230.

Fisher, M. C., S. H. Zeisel, M. H. Mar, and T. W. Sadler. 2002. Perturbations in choline metabolism cause neural tube defects in mouse embryos in vitro. FASEB J. 16:619-621. https://doi.org/10.1096/ fj.01-0564fje.

Glier, M. B., T. J. Green, and A. M. Devlin. 2014. Methyl nutrients, DNA methylation, and cardiovascular disease. Mol. Nutr. Food Res. 58:172-182. https://doi.org/10.1002/mnfr.201200636.

Graf, A., S. Krebs, V. Zakhartchenko, B. Schwalb, H. Blum, and E. Wolf. 2014. Fine mapping of genome activation in bovine embryos by RNA sequencing. Proc. Natl. Acad. Sci. USA 111:4139-4144. https://doi.org/10.1073/pnas.1321569111.

Hosseini, S. M., I. Dufort, J. Caballero, F. Moulavi, H. R. Ghanaei, and M. A. Sirard. 2015. Transcriptome profiling of bovine inner cell mass and trophectoderm derived from in vivo generated blas- 
tocysts. BMC Dev. Biol. 15:49. https://doi.org/10.1186/s12861 -015-0096-3.

Ikeda, S., T. Namekawa, M. Sugimoto, and S. Kume. 2010. Expression of methylation pathway enzymes in bovine oocytes and preimplantation embryos. J. Exp. Zool. A Ecol. Genet. Physiol. 313:129-136. https://doi.org/10.1002/jez.581.

Iwao, B., M. Yara, N. Hara, Y. Kawai, T. Yamanaka, N. Nishihara, T. Inoue, and M. Inazu. 2016. Functional expression of choline transporter like-protein 1 (CTL1) and CTL2 in human brain microvascular endothelial cells. Neurochem. Int. 93:40-50. https:// doi.org/10.1016/j.neuint.2015.12.011.

Jiang, Z., J. Lin, H. Dong, X. Zheng, S. L. Marjani, J. Duan, Z. Ouyang, J. Chen, and X. C. Tian. 2018. DNA methylomes of bovine gametes and in vivo produced preimplantation embryos. Biol. Reprod. 99:949-959. https://doi.org/10.1093/biolre/ioy138.

Jiang, Z., J. Sun, H. Dong, O. Luo, X. Zheng, C. Obergfell, Y. Tang, J. Bi, R. O'Neill, Y. Ruan, J. Chen, and X. C. Tian. 2014. Transcriptional profiles of bovine in vivo pre-implantation development. BMC Genomics 15:756. https://doi.org/10.1186/1471-2164 $-15-756$.

Lee, K. S., R. M. Squillace, and E. H. Wang. 2007. Expression pattern of muscleblind-like proteins differs in differentiating myoblasts. Biochem. Biophys. Res. Commun. 361:151-155. https://doi.org/ 10.1016/j.bbrc.2007.06.165.

Lee, M. B., M. Kooistra, B. Zhang, S. Slow, A. L. Fortier, T. A. Garrow, M. Lever, J. M. Trasler, and J. M. Baltz. 2012. Betaine homocysteine methyltransferase is active in the mouse blastocyst and promotes inner cell mass development. J. Biol. Chem. 287:3309433103. https://doi.org/10.1074/jbc.M112.365478.

Negrón-Pérez, V. M., and P. J. Hansen. 2018. Role of yes-associated protein 1 , angiomotin, and mitogen-activated kinase kinase 1/2 in development of the bovine blastocyst. Biol. Reprod. 98:170-183. https://doi.org/10.1093/biolre/iox172.

Negrón-Pérez, V. M., Y. Zhang, and P. J. Hansen. 2017. Single-cell gene expression of the bovine blastocyst. Reproduction 154:627644. https://doi.org/10.1530/REP-17-0345.

Peñagaricano, F., A. H. Souza, P. D. Carvalho, A. M. Driver, R. Gambra, J. Kropp, K. S. Hackbart, D. Luchini, R. D. Shaver, M. C. Wiltbank, and H. Khatib. 2013. Effect of maternal methionine supplementation on the transcriptome of bovine preimplantation embryos. PLoS One 8:e72302. https://doi.org/10.1371/journal .pone.0072302.

Pfeffer, P. L. 2018. Building principles for constructing a mammalian blastocyst embryo. Biology (Basel) 7:41. https://doi.org/10.3390/ biology7030041.

Ridgway, N. D. 2013. The role of phosphatidylcholine and choline metabolites to cell proliferation and survival. Crit. Rev. Biochem. Mol. Biol. 48:20-38. https://doi.org/10.3109/10409238.2012 .735643 .

Roche, J. R., C. R. Burke, S. Meier, and C. G. Walker. 2011. Nutrition $\mathrm{x}$ reproduction interaction in pasture-based systems: is nutrition a factor in reproductive failure? Anim. Prod. Sci. 51:1045-1066. https://doi.org/10.1071/AN10162.

Rodney, R. M., P. Celi, W. Scott, K. Breinhild, J. E. P. Santos, and I. J. Lean. 2018. Effects of nutrition on the fertility of lactating dairy cattle. J. Dairy Sci. 101:5115-5133. https://doi.org/10.3168/ jds.2017-14064.

Scheer-Oelrichs, W. A. 2003. The effects of feeding soybeans and rumen protected choline during the periparturient period and early lactation on production and reproduction of dairy cows. PhD Diss. Univ. Missouri, Columbia.

Shojaei Saadi, H. A., D. Gagné, E. Fournier, L. M. Baldoceda-Baldeon, M.-A. Sirard, and C. Robert. 2016. Responses of bovine ear- ly embryos to S-adenosyl methionine supplementation in culture. Epigenomics 8:1039-1060. https://doi.org/10.2217/epi-2016-0022.

Spangle, J. M., T. M. Roberts, and J. J. Zhao. 2017. The emerging role of PI3K/AKT-mediated epigenetic regulation in cancer. Biochim. Biophys. Acta Rev. Cancer 1868:123-131. https://doi.org/ 10.1016/j.bbcan.2017.03.002.

Toledo, M. Z., G. M. Baez, A. Garcia-Guerra, N. E. Lobos, J. N. Guenther, E. Trevisol, D. Luchini, R. D. Shaver, and M. C. Wiltbank. 2017. Effect of feeding rumen-protected methionine on productive and reproductive performance of dairy cows. PLoS One 12:e0189117. https://doi.org/10.1371/journal.pone.0189117.

Tríbulo, P., L. Balzano-Nogueira, A. Conesa, L. G. Siqueira, and P. J. Hansen. 2019a. Changes in the uterine metabolome of the cow during the first 7 days after estrus. Mol. Reprod. Dev. 86:75-87. https://doi.org/10.1002/mrd.23082.

Tríbulo, P., R. M. Rivera, M. S. Ortega-Obando, E. A. Jannaman, and P. J. Hansen. 2019b. Production and culture of the bovine embryo. Methods Mol. Biol. 2006:115-129. https://doi.org/10.1007/978-1 -4939-9566-0_8.

van der Veen, J. N., S. Lingrell, N. McCloskey, N. D. LeBlond, D. Galleguillos, Y. Y. Zhao, J. M. Curtis, S. Sipione, M. D. Fullerton, D. E. Vance, and R. L. Jacobs. 2019. A role for phosphatidylcholine and phosphatidylethanolamine in hepatic insulin signaling. FASEB J. 33:5045-5057. https://doi.org/10.1096/fj.201802117R.

Wiltbank, M. C., G. M. Baez, A. Garcia-Guerra, M. Z. Toledo, P. L. J. Monteiro, L. F. Melo, J. C. Ochoa, J. E. P. Santos, and R. Sartori. 2016. Pivotal periods for pregnancy loss during the first trimester of gestation in lactating dairy cows. Theriogenology 86:239-253. https://doi.org/10.1016/j.theriogenology.2016.04.037.

Wooldridge, L. K., S. E. Johnson, R. R. Cockrum, and A. D. Ealy. 2019. Interleukin- 6 requires JAK to stimulate inner cell mass expansion in bovine embryos. Reproduction 158:303-312. https://doi .org/10.1530/REP-19-0286.

Wu, G., Ch. Aoyama, S. G. Young, and D. E. Vance. 2008. Early embryonic lethality caused by disruption of the gene for choline kinase, the first enzyme in phosphatidylcholine biosynthesis. J. Biol. Chem. 283:1456-1462. https://doi.org/10.1074/jbc.M708766200.

Yu, H., Z. Zhao, X. Yu, J. Li, C. Lu, and R. Yang. 2017. Bovine lipid metabolism related gene GPAM: Molecular characterization, function identification, and association analysis with fat deposition traits. Gene 609:9-18. https://doi.org/10.1016/j.gene.2017.01.031.

Zeisel, S. 2017. Choline, other methyl-donors and epigenetics. Nutrients 9:445. https://doi.org/10.3390/nu9050445.

Zenobi, M. G., R. Gardinal, J. E. Zuniga, A. L. G. Dias, C. D. Nelson, J. P. Driver, B. A. Barton, J. E. P. Santos, and C. R. Staples. 2018a. Effects of supplementation with ruminally protected choline on performance of multiparous Holstein cows did not depend upon prepartum caloric intake. J. Dairy Sci. 101:1088-1110. https: //doi.org/10.3168/jds.2017-13327.

Zenobi, M. G., T. L. Scheffler, J. E. Zuniga, M. B. Poindexter, S. R. Campagna, H. F. Castro Gonzalez, A. T. Farmer, B. A. Barton, J. E. P. Santos, and C. R. Staples. 2018b. Feeding increasing amounts of ruminally protected choline decreased fatty liver in nonlactating, pregnant Holstein cows in negative energy status. J. Dairy Sci. 101:5902-5923. https://doi.org/10.3168/jds.2017-13973.

\section{ORCIDS}

E. Estrada-Cortés (® https://orcid.org/0000-0003-0226-9794

V. M. Negrón-Peréz @ https://orcid.org/0000-0001-8363-4823

C. R. Staples @ https://orcid.org/0000-0002-0237-946X

P. J. Hansen ํ) https://orcid.org/0000-0003-3061-9333 